\title{
WHOOPING CRANE WITH LEG BAND SIGHTED NEAR MOSSBANK, SK
}

I went out Nov 12, 2012, about 5 miles west of Mossbank, and saw a pair of Whooping Cranes. I wish I could have got closer, they were quite far away, but I didn't want to scare them. Over the years I have seen more Whooping Cranes, but this seems to me very late for them to be here. When I worked on the farm back in the 1950's, six Whooping Cranes came out of Old Wives' Lake, and as I remember they stayed around for about a week or so, but that was in September. I went out to look for the cranes the next day (Nov 13, 2012) and got a little closer to them. I could see with my binoculars that one of the cranes had a band on its leg.

- Don Smith, Box 202, Mossbank SK. SOH $3 G 0$
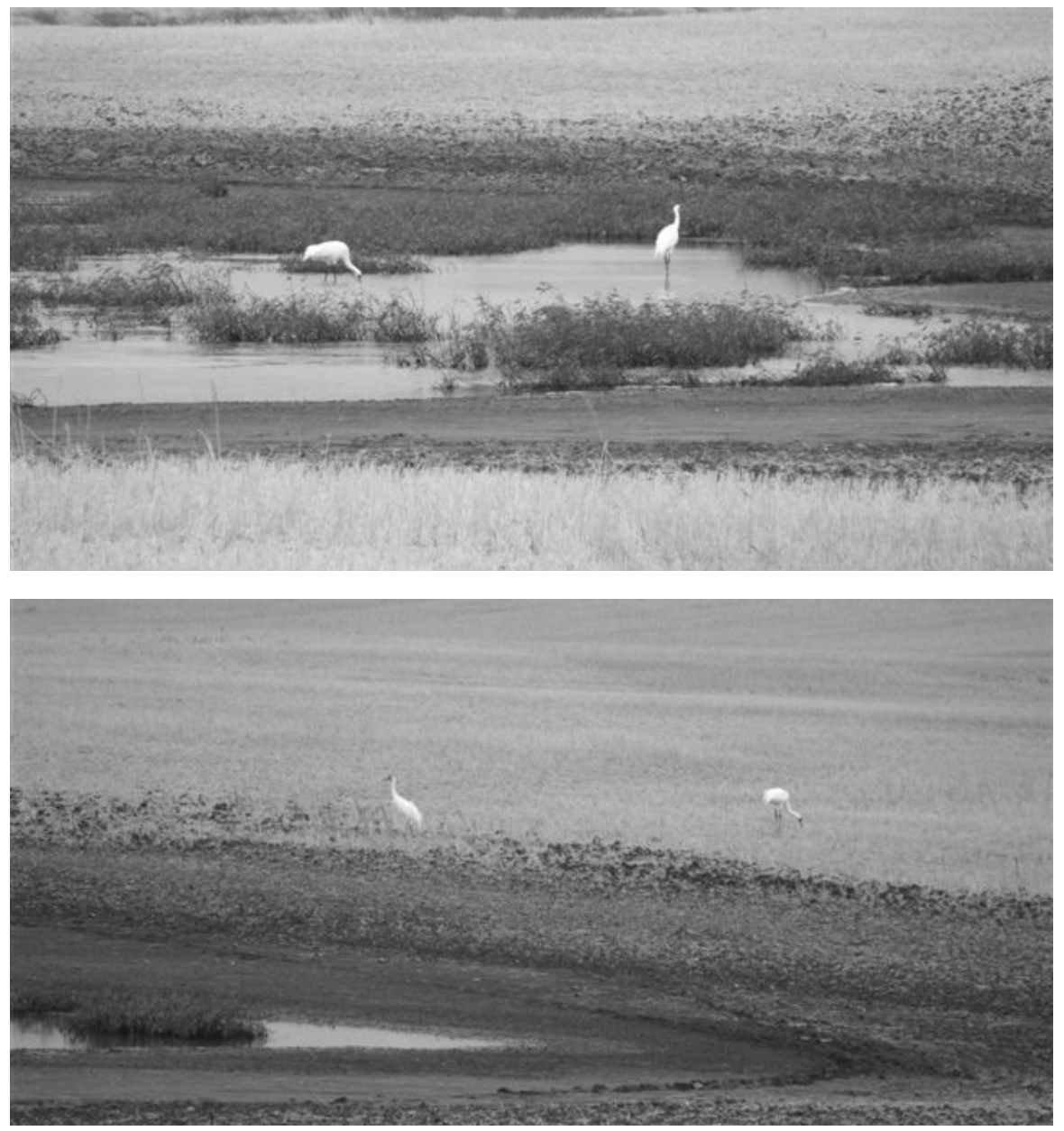